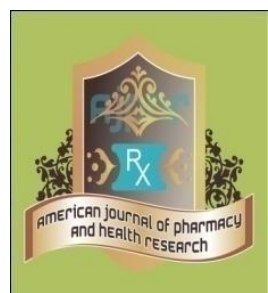

Review Article AMERICAN JOURNAL OF PHARMACY AND HEALTH RESEARCH www.ajphr.com 2020, Volume 8, Issue 5 ISSN: 2321-3647(online)

\title{
Clove (Syzygium Aromaticum): A Miraculous Spice
}

\author{
Nitin S Gosavi ${ }^{1}$ *, Swapnil S Koli ${ }^{1}$, Davesh S Jire ${ }^{1}$, Azam Z. Shaikh ${ }^{1}$. \\ 1.Department of Pharmacognosy, Ahinsa Institute of pharmacy Dhule road Dondaicha 425408
}

\begin{abstract}
Clove (Syzygium aromaticum) is one of the most valuable spices that has been used as food preservatives and also used for the treatment of various medical conditions like dentistry and research confirms it is effective at inhibiting the growth of foodborne pathogens, certain bacteria, and fungi. They are native to the Maluku Islands in Indonesia and are commonly used as a spice, sold both whole and ground. Japanese researchers have discovered that like Eugenia Caryophyllus (also known as clove oil) contains antioxidant properties which help prevent the cell spoil in time causes malignant disease. Buds are harvested when they are under an inch (less than $2 \mathrm{~cm}$.) long, before they turn pink and open. Clove consist of Eugenol (up to 90\%), acetyl eugenol, beta-caryophyllene and vanillin; crategolic acid; tannins etc. A dose of 40 to $60 \mathrm{ppm}$ eugenol was found to induce quick anesthesia with a relatively short time for recovery in young trout.
\end{abstract}

Keyword: Clove, Eugenol, Volatile, Spice, Anesthesia. 


\section{INTRODUCTION}

Spices as clove, oregano, mint, thyme and cinnamon, have been working for centuries as food preservatives and as medicinal plants mainly due to its antioxidant and antimicrobial activities. Now a days, many reports confirm the antibacterial, antifungal, antiviral and anticarcinogenic properties of spice plants. Clove in exacting has concerned the attention due to the potent antioxidant and antimicrobial activities standing out among the other spices ${ }^{[1]}$.

Syzygium aromaticum (S. aromaticum) (synonym: Eugenia cariophylata) commonly known as clove, is an median size tree (8-12) from the Mirtaceae family local from the Maluku islands in east Indonesia. For centuries the trade of clove and the investigate of this important spice encouraged the financial growth of this Asiatic region ${ }^{[2]}$.

The clove tree is commonly cultivated in coastal areas at maximum altitudes of $200 \mathrm{~m}$ above the sea level. The manufacture of flower buds, which is the commercialized part of this tree, starts after 4 years of plantation. Flower buds are collected in the maturation phase before flowering. The collection could be done manually or chemically-mediated using a natural maturation ${ }^{[3]}$.

Nowadays, the larger producer countries of clove are Indonesia, India, Malaysia, Sri Lanka, Madagascar and Tanzania specially the Zanzibar island ${ }^{[2]}$. In Brazil, clove is cultivated in the northeast region, in the state of Bahia in the regions of Valença, Ituberá, Taperoá, Camamu and Nilo Peçanha, where just about 8000 hectares are cultivated, produce near 2500 tons per year $^{[4][5]}$.

\section{Biological Source:}

Clove consists of the dried flower buds of Eugenia caryophyllus Thumb, belonging to family Myrtaceae.

Eugenia Caryophyllus.

An component distilled from the dried flowerbuds of Eugenia caryophyllus Also known as clove oil.

Eugenia Caryophyllus, or cloves, were usually used to kill intestinal parasites thanks to their large anti-microbial properties against fungi and bacteria, thus supporting its traditional use as a treatment for diarrhea, intestinal worms and other digestive ailments. These anti-microbial properties also explain its use in deodorants and anti-fungal powders. According to Artemis Herbs, Japanese researchers have discovered that like Eugenia Caryophyllus contains antioxidant properties which help prevent the cell spoil in time causes malignant disease. However, the chemical eugenol has been found to be a weak tumor promoter, making this element one of many remedial herbs with both pro- and anti-cancer effects. 
An ingredient distilled from the dried flower buds of Eugenia caryophyllus

Also known as clove oil ${ }^{[6]}$

\section{Function:-}

Eugenia Caryophyllus, or cloves, were usually used to kill intestinal parasites thanks to their large anti-microbial properties against fungi and bacteria, thus supporting its traditional use as a treatment for diarrhea, intestinal worms and other digestive ailments. These anti-microbial properties also explain its use in deodorants and anti-fungal powders. According to Artemis Herb Japanese researchers have discovered that like Eugenia Caryophyllus contains antioxidant properties which help avoid the cell spoil in the end causes malignant disease. However, the chemical eugenol has been found to be a weak tumor promoter, making this ingredient one of many therapeutic herbs with both pro- and anti-cancer effects ${ }^{[7]}$

\section{Common Name:-}

\section{Syzygium aromaticum}

Clove, (Syzygiumaromaticum), tropical evergreen tree of the family Myrtaceae and its small reddish brown flower buds used as a spice. ${ }^{[8]}$

\section{Botanical Name}

\section{Syzygium aromaticum}

Cloves are the sweet-smelling dried flower buds of a tree in the family Myrtaceae, Syzygium aromaticum. Cloves are local to the Maluku islands in Indonesia and used as a spice in cuisines all over the world. Cloves are harvested mainly in Indonesia, India, Madagascar, Zanzibar, and Sri Lanka. They have a numbing effect on mouth tissues.

The clove tree is an evergreen that grows to a height ranging from 8-12 $\mathrm{m}$, having large leaves and sanguine flowers in numerous groups of terminal clusters. The flower buds are at first of a pale color and gradually become green, after which they enlarge into a bright red, when they are ready for collect. Cloves are harvested when $1.5-2 \mathrm{~cm}$ long, and consist of a long calyx, terminating in four spreading sepals, and four unopened petals which form a small ball in the center. $^{[9]}$

\section{Harvesting and processing:-}

The trees begin to flower in 6 years. Full bearing is achieved by about 20 years and the invention continues for 80 years or more. Bearing between years shows a large amount disparity. Clove cluster are select, when the buds reach full size and turn pink but before they open. At this stage, they are less than $2 \mathrm{~cm}$ long. They are widen thinly on mats and stirred commonly for identical drying. Well dried up cloves will snap minimally with a pointed click across the thumb nail and 
weigh about one third of the green weight. The opened flowers are not appreciated as a spice. Harvesting has to be done without harmful the twigs, as it unfavorably affects the following growth of the trees. On an average, a clove tree yields 3.5-7.0 kg/year, depending upon the age, size and condition of the tree.
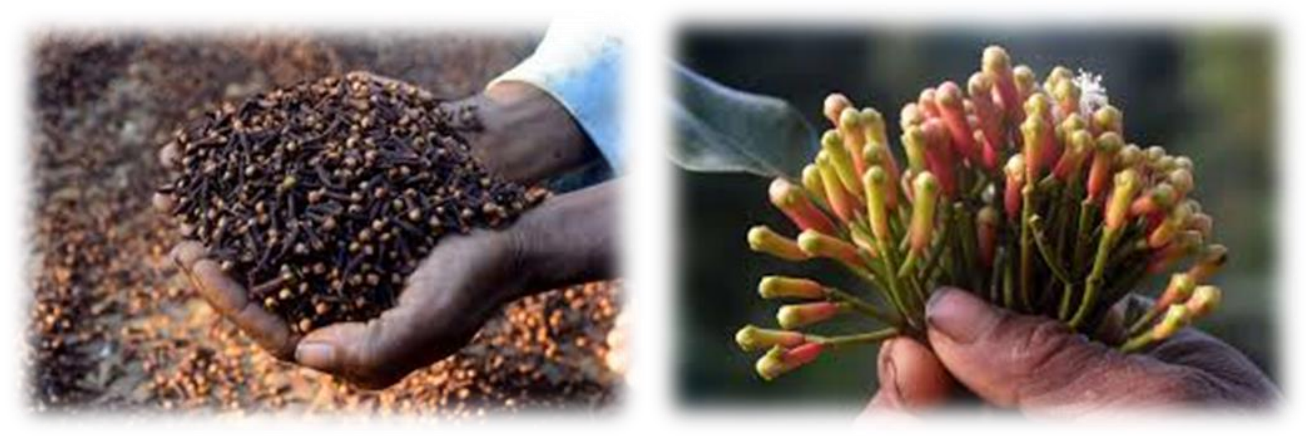

\section{Climate and soil:-}

Clove trees grow well in wealthy loamy soils of the moist tropics and can be grown successfully in the red soils of the midlands of Kerala as well as in the hilly terrain of Western Ghats at higher elevation in Tamil Nadu and Karnataka. A cooler weather with well dispersed rainfall is ideal for flowering; it thrives well in areas getting a yearly rainfall of 150-300 cm. The site chosen for farming of clove needs good drainage, since crop cannot withstand water logging.

\section{Post-Harvesting Technology:}

Clove trees begin to flower in four years and the full manner stage is achieved only in 15 years. Flowering period varies from September-October to December-January depending on tree area. Clove buds are formed on youthful branches and take 4-6 months to become ready for harvest. Buds should be harvested when color of petals changes to yellow pink from green. Harvesting can be done by hand or by using ladder. Harvesting should be done carefully to prevent breakage of branches. An average 15 to 20 year old tree yields 3 to $4 \mathrm{~kg}$ of dried clove buds. most favorable time for harvesting clove seeds is 75-90 days after fruit set. After harvesting, clove buds are divided from their stalk by hand and spread on mats for drying. Drying may take 4 to 5 days. Well dried buds are hard, crunchy and dark brown, having damp content $(<12 \%)$, which can be stored for 1 to 2 years in gunny bags. just about, 15-20\% volatile oil can be formed from dried buds ${ }^{[10]}$.

\section{Chemical Constituents:}

Three vital oils are available from clove species: Clove bud oil, Clove stem oil, and Clove leaf oil. Each has dissimilar chemical composition and flavor. Clove bud oil, the most costly and the layer quality product, contain eugenol (80-90\%), eugenol acetate (15\%), and beta caryophyllene (5-12\%).Another important compound found in the essential oil of clove in 
concentration up to $2.1 \%$ is alpha -Humulin. Eugenol composes $72-90 \%$ of the essential oil extract from cloves and is the compound most dependable for aroma. 100\% extraction occurs at 80 minutes in under pressure water of $125^{\circ} \mathrm{C}$. Ultrasound -assisted and microwave -assisted removal methods provide more rapid pleasing out rates with lower energy costs. ${ }^{[1]}$

\section{Other important chemical constituents:-}

1. Volatile oil (Clove oil ) : 15\%-20\%

a-Eugenol 70\%-90\%

b-Vanillin

c-Caryophyllene

d-Acetyl eugenol 4\%

1.Tannin : 10-13\%( Gallo tannic acid)

2.Resin 4.chromone 5.Eugenin

3.Small quantities of esters, ketones, alcohols

4.Other substances mainly methyl furfural and dimethyl furfural. ${ }^{[12]}$

\section{Volatile Constituents:-}

Clove yield dissimilar types of volatile oil [oil extracted from i. leaves, ii. the stem, iii. the buds and iv. the fruit.] These oils be at variance significantly in yield and quality. The yield and composition of the oil obtained are unfair by its origin, season, variety and quality of raw material, maturity at harvest, pre- and post-distillation treatments and method of distillation. The ruler constituent of all the types of oil is eugenol.

\section{Bud Oil:}

Good-quality clove buds contain $15-20 \%$ essential oil ${ }^{[13][14]}$. The oil is dominated by Eugenol (70-85\%), eugenyl acetate (15\%) and $\beta$-caryophyllene (5-12\%), which together make up $99 \%$ of the oil. The constituents of the oil also include methyl amylketone, methyl salicylate, $\alpha$ - and $\beta$ humulene, benzaldehyde, $\beta$-ylangene and chavicol. The minor constituents like methyl amylketone, methyl salicylate etc., are responsible for the characteristic pleasant odour of cloves. The clove bud and stem oils from Madagascar were also subjugated by eugenol, eugenyl acetate and $\beta$-caryophyllene. The stem oil contained a higher level of eugenol, whereas the eugenyl acetate content was higher in the bud oil. The oil from clove bud contained $73.5-79.7 \%$ eugenol and 4.5-10.7\% eugenyl acetate, while the stem oil contained 76.4-84.8\% eugenol and 1.5-8.0\% eugenyl acetate. Both contained 7.3-12.4\% $\beta$-caryophyllene and 1.0-1.4\% $\alpha$-humulene ${ }^{3}$. Pino et al. identified 36 compounds from the volatile oil of clove buds. Clove buds from India contained 
12.9- $18.5 \%$ oil, of which $44-55 \%$ was eugenol, whereas the pedicels contained $3.0-7.7 \%$ oil with $60.0-72.4 \%$ eugenol $^{[14]}$.

\section{Leaf Oil:-}

Clove leaves yield 3.0-4.8\% essential oil. The essential oil content during the different stages of leaf growth exposed that the eugenol content in the leaves increased from 38.3 to $95.2 \%$ with maturity, while the contents of eugenyl acetate (51.2 to $1.5 \%)$ and caryophyllene (6.3 to $0.2 \%)$ decreased $^{[15]}$. Clove bud and leaf oil contain various classes of compounds, e.g. monoterpenes, sesquiterpenes, aldehydes and ketones.

\section{Clove Stem Oil:-}

Clove stem yields $6 \%$ volatile oil ${ }^{[13]}$. The oil is a pale to light yellow liquid containing $80.2 \%$ eugenol and $6.6 \% \beta$-caryophyllene, besides several minor components.

\section{Fruit Oil:-}

Ripe fruits yield $2 \%$ of oil, which is comprised of $50-55 \%$ eugenol.

\section{Non-volatile Constituents:-}

A few non-volatiles have been isolated from clove, which include tannins, sterols, triterpenes and flavonoids.

\section{Tannins:-}

Cloves contain 10-13\% tannins, which have the same chemical composition as gallotannic acid. Eugenin and ellagitannin ${ }^{[16]}$ were isolated from cloves. Eugenol glucoside gallate, a chromone $C$ glycoside, galloyl and hexahydroxy diphenyl esters of 2, 4, 6-trihydroxy acetophenone- 3glucopyranoside were isolated from clove leaves ${ }^{[17]}$. Further, two ellagitannins, namely, syzyginin A (1, 2, 3-tri- $O$-galloyl-4, 6- $(S)$ - tergalloyl- $\beta$ - D-glucoside) and syzyginin $\mathrm{B}$, were also isolated from the leaves.

\section{Triterpenes:-}

Cloves contain about $2 \%$ of the triterpene, oleanolic acid. Narayanan and Natu (1974) isolated maslinic acid from clove buds ${ }^{[18]}$. From clove, $2 \alpha$-hydroxyoleanolic acid was also isolated ${ }^{[19]}$.

\section{Sterols:-}

Sterols isolated from clove include sitosterol, stigmasterol and campesterol ${ }^{[19]}$.

\section{Flavonoids:}

A chromone C-glucoside, isobiflorin (5, 7-dihydroxy-2- methoxychromone-8-C- $\beta$-Dglucopyranoside) and biflorin were isolated from the ethanolic extract of cloves ${ }^{[20]}$. From the ethanol extract of the seeds, apigenin $6-C-[\beta-D-x y l o p y r a n o s y l-(1 \rightarrow 2 ")-\beta-D-$ galactopyranoside]- 
7-O- $\beta$-D-glucopyranoside and apigenin-6-C-[ $\beta$-D-xylopyranosyl- $\left(1 \rightarrow 22^{\prime \prime}\right)-\beta$-Dgalactopyranoside]-7-O- $\beta$-D-(6-O-p- coumarylglucopyranoside) were isolated $^{[21]}$.

\section{Medicinal uses:}

- Clove is known to possess antibacterial properties and is used in various dental creams, tooth pastes, mouth washes, and throat sprays to cleanse bacteria. It is also used to relive pain from sore gums and improves overall dental health.

- In dentistry, eugenol in combination with zinc oxide is used for provisional filling of cavities.

- Clove is an anodyne (an agent that soothes or relives pain) for dental emergencies ${ }^{[22]}$.

- Cloves are aphrodisiac (an agent for arousing or increasing sexual desire or potency).

- Clove is used as an anti-inflammatory agent, due to its high content of flavonoids. Aroma therapists use pure clove oil to cure the symptoms of rheumatism and arthritis.

- Clove is used as a carminative, to increase hydrochloric acid in the stomach and to improve peristalsis.

- Apply the paste of clove powder in honey to treat spots. Paste of clove powder in water promotes faster healing of cut and bite.

- Cloves can efficiently cure many digestive problems. It is having medicinal qualities to cure flatulence, loose motions, indigestion and nausea. Cloves are useful in relieve the symptoms of diarrhea, gastric irritability and vomiting.

- Clove and clove oil boost the protected system by purifying the blood and help to fight against various diseases.

- Clove oil is effective in remedial Athlete's foot and nail fungus.

- Cloves are good expectorants that promote the free of mucous and secretions in the respiratory passage.

- The aromatic clove oil, when inhaled can help calm positive respiratory conditions like cold, cough, asthma, bronchitis, and sinusitis. It also helps in clearing the nasal tract.

- Cloves can successfully prevent the lung cancer as well as the skin cancer. Eugenol helps in minimizing the harmful effects of environmental wastes that can cause cancer of digestive system.

- Clove oil stimulate blood flow and circulation making it useful for the people having cold extremity.

- Cloves benefit the diabetic patients by controlling the blood glucose levels. Eugenol is powerful enough for preventing blood clots. 
- Sucking of a clove bud reduce desire for alcohol. Muscular cramps are often relieved, when the oil of clove is applied as a poultice near the affected area.

- Cloves also help prevent the stop working in retina of the eye, which slows down macular collapse and aids vision in the old age. The underlying mechanism is through the prevention of the breakdown of docosahexaenoic acid, which preserves vision in elderly people.

- Researchers found that sniffing the spicy aroma of cloves reduces drowsiness, irritability and headaches.

- One drop of clove oil applied to the roof of the mouth can instantly relieve many headaches.

- Clove enhances memory retention. It is recommended for relieving brain fog, lethargy and depressive state of mind. Research has shown that clove oil is an effective mosquito repellent ${ }^{[23]}$.

- Clove may be looked upon as the champion of all the anti-oxidants known till date. The Oxygen Radical Absorption Capacity test (ORAC) is a scale developed by

- U.S. Department of Agriculture for comparing anti- oxidant activity. The ORAC score, of clove is over 10 million. A drop of clove oil is 400 times more powerful as an antioxidant than wolf berries or blueberries

\section{Uses of clove in dentistry:-}

\section{1) Dental care:}

The most prominent use of clove oil in dental care. The germicidal properties of the oil make it very effective for relieve dental pain, tooth ache, sore gums and mouth ulcers. Clove oil contains the composite eugenol, which has been used in dentistry since numerous years. Gargles with diluted clove oil help in easing the throat. The character smell of clove oil helps removing bad breath. As a result, clove oil is added to numerous dental products and medications, including, mouth washes, and tooth pastes. Dentists also mix clove oil with zinc oxide and prepare a white filling material as a temporary alternative to root canal. ${ }^{[24]}$

\section{2) Oral thrush:-}

Oral thrush, also called oral candidiasis, is a yeast infectivity of the mouth. It happens when there's a build-up of the Candida albicans fungus in the coating of the mouth. Oral thrush may occur in adults or children. Clove oil, it's still in dentistry today as antiseptic and pain reliever. According to a 2005 in vivo and in vitro study on immunosuppressed rat, the main compound in clove oil (eugenol) was found to be as effective in treating oral thrush as the antifungal drug 
nystatin. Clove contain eugenol is the most powerful of these, with antiseptic properties that have been shown to kill the Candida yeast cells. Eugenol is also an immune system stimulant, which means it helps to increase the body's disease fighting powers. ${ }^{[25]}$

\section{3) Treat Infections:-}

Due to its antiseptic properties, clove oil is useful for wound, cuts, scabies, athlete's foot, fungal infections, bruises, prickly heat, scabies etc. It can also be used insect bites and stings. ${ }^{[26]}$

\section{4) Stress:-}

Clove oil is aphrodisiac in nature and hence serves as an outstanding stress reliever. It has a exciting effect on the mind and removes mental collapse and fatigue. When taken internally, in proper amounts, it refreshes the mind. Clove oil also induces the sleeps and is helpful to insomnias patients. It is useful for treating mental problems such as loss of memory, depression and anxiety. ${ }^{[27]}$

\section{5) Respiratory problems:-}

Clove oil has a cooling and anti -inflammatory effect, and in this manner clear the nasal passage. This expectorant is useful in various respiratory disorders including coughs, colds, bronchitis, asthma, sinusitis, and tuberculosis. ${ }^{[28]}$

\section{Dosage:}

The clove and clove oil are used safely. The level of clove used in foods does not exceed $0.24 \%$; the oil is not used in amounts larger than $0.06 \%$. Clove oil can be used topically, with a 1:1 ratio of clove oil to carrier oil (fractionated coconut oil), and useful to area of concern or reflex points. Oral health- Clove oil is widely accepted as a valuable solution for toothaches, dry sockets. Dilute 1 drop clove oil with 1 drop carrier oil and apply to area of concern Parasites- Take 2 drops clove oil internally, in capsules, for up to 10 days to create a inhospitable environment for parasites.

Oxidative stress-Dilute 2 drops with equal parts carrier oil, and apply topically to neck and chest to prevent free radical damage.

Fungal and Yeast - balance clove contain anti-fungal properties. Add 1 drop of clove oil to herbal tea and consume for up to 10 days.

Acne- Clove oil is a natural antibacterial and can help fight acne and other skin issues. Combine 3 drops of clove oil with 2 teaspoons of raw (local is best) honey and apply to face Let sit for 10 minutes, then rinse off. ${ }^{[29]}$

\section{PHARMACOLOGICAL ACTIVITY}

\section{Antimicrobial activity:-}


Antimicrobial properties of Syzygium aromaticum and Rosmarinus officinalis essential oils were tested against multidrug resistant isolates including Pseudomonas aeruginosa, Enterococcus feacalis, Acinetobacter baumannii, and Staphylococcus aureus, and two controlled strains Pseudomonas aeruginosa-ATCC27853 and Staphylococcus aureus-ATCC29213, using agar well distribution model. Both oils exhibit major inhibition against tested strains, with minimum inhibitory concentrations ranging from $0.312-1.25 \%(\mathrm{v} / \mathrm{v})$ for clove oil, and $0.312-5 \%(\mathrm{v} / \mathrm{v})$ for rosemary oil. ${ }^{[30]}$ A relative analysis was carried out to calculate the antiseptic potential of clove take out (ethanolic) and clove oil against some food bear pathogens. Ten bacterial and seven fungal strains were tested using agar well diffusion method. Sodium propionate was used as a standard food additive. Results revealed the greater antimicrobial effect of clove oil, when compared to extract and sodium propionate. In another study, clove oil was tested against five dermophytes including Trichophyton rubrum, Epidermophyton floccosum, Microsporum canis, Microsporum gypseum, and Trichophyton mentagrophytes. Maximum inhibitory effect ( $\approx 60 \%)$ against all fungal strains was shown at dose of $0.2 \mathrm{mg} / \mathrm{ml} .^{[31]}$ Antibacterial activity of six spices (clove, mint, cinnamon, ginger, mustard, and garlic) was evaluated against Escherichia coli, Bacillus cereus, and Staphylococcus aureus, using dilution, cup, and paper disc diffusion assays. Results revealed the maximum inhibitory action of clove, mustard, and cinnamon at $1 \%$ concentration. Garlic showed good inhibitory action at 3\% concentration. However, mint and ginger had negligible inhibition at same concentration. ${ }^{[32]}$ Essential oils of Piper nigrum, Syzygium aromaticum, Pelargonium graveolens, Myristica fragrans, Origanum vulgare, and Thymus vulgaris were evaluated for antimicrobial activity against twenty five bacterial strains, including food borne, animal, and plant pathogens. considerable inhibitory action was observed by the volatile oils in a dose reliant actions. ${ }^{[33]}$

\section{Cytotoxic activity:-}

Anti-oxidant, genotoxic and cytotoxic potentials of borneol and eugenol (clove oil derivative) were evaluated as the ability of modulate resistance against DNA damaging effects of $\mathrm{H}_{2} \mathrm{O}_{2}$, on dissimilar strains of human cells: malignan hepatome cells (HepG2), malignan colon cells (caco2) and non malignan human fibroblast (VH10). Results exposed the notable anti-oxidative potential of eugenol at all the tested doses. It was also confirmed that the citotoxic potential of eugenol was more powerful than borneol. With regard to toxicity, eugenol exhibited strong DNA damaging effects on human fibroblast (VH10), medium damaging effects on colon cells (caco-2) and non genotoxic effects on hepatome cells (HepG2). ${ }^{[34]}$

\section{Antioxidant activity:-}


A study was performed to assess the antioxidant potential of aqueous and alcohol extracts of some selected spices including onion, garlic, pepper, cinnamon, mint, ginger, and clove. Generally phenolic and flavonoids are dependable for antioxidant activities of the oil ${ }^{[35]}$. All spices reserved lipid oxidation in a dose dependent manner. Among all, clove showed maximum, whereas, onion showed minimum inhibitory potential ${ }^{[36]}$. Antioxidant activities of clove, sage, and oregano essential oils were evaluate using DPPH (2, 2-diphenyl-1-picrylhydrazyl) free radical quenching, BCB ( $\beta$-carotene bleaching), and FRP (Fe(lll) reducing power) methods. Butylated hydroxytoluene was used as standard antioxidant. Essential oils were added to soybean oil at doses of 0.006 and $0.01 \mathrm{~g} / \mathrm{ml}$, for thirty days, at accelerate oxidation level. Among all examined oils, the clove oil showed more potent $(\mathrm{p}<0.05)$ antioxidant activity followed by oregano and sage oils ${ }^{[37]}$

.Antiviral activity:-

Eugenin isolated from clove bud essential oil exhibit a effective inhibitory effect against herpes simplex virus at a dose of $10 \mu \mathrm{g} / \mathrm{ml}^{[38]}$.

\section{Hepatoprotective activity:-}

Hepatoprotective potential of clove aqueous extract was evaluated at doses of 0.1 and $0.2 \mathrm{~g} / \mathrm{kg}$, using paracetamol high hepatic damage assay, in Wistar albino rats. The degree of hepatic damage was evaluated by increased levels of cytopalsmic enzymes (aspartate aminotransferase and alanine aminotransferase). Clove extract restored the normal concentrations of enzymes in serum $^{[39]}$.

\section{Analgesic activity:-}

Eugenol was administrated intravenously and intragastrically to rabbits to examine its analgesic effect. Paracetamol was a standard drug. Eugenol showed greater fever falling potential than paracetamol $^{[40]}$.

\section{Anesthetic activity:-}

Anesthetic effect of eugenol was studied in Oncorhynchus mykiss (juvenile rainbow trout). Anesthesia induction and recovery times were compared with standard drug, tricaine methanesulfonate (MS-222). Eugenol induced anaesthesia at relatively lower concentration than standard drug. Moreover, the recovery time was 6-10 times longer for fishes exposed to eugenol than those exposed to same doses of tricaine methanesulfonate. Above study optional the anesthetic use of clove oil derivative "Eugenol" [41].

\section{Toxicity:-}


The clove oil is considered safe when consumed in doses $(<1.5 \mathrm{~g} / \mathrm{kg})$. However, the WHO (World Health Organization) recognized the acceptable dose of clove $2.5 \mathrm{mg} / \mathrm{kg} / \mathrm{day}$ in humans. The toxicity of clove oil was evaluated in aquarium fish species, Poecilia reticulata and Danio rerio. The LD50 values were $(18.2 \pm 5.52) \mathrm{mg} / \mathrm{ml}$ and $(21.7 \pm 0.8) \mathrm{mg} / \mathrm{ml}$ in Danio rerio and Poecilia reticulate, correspondingly, at $96 \mathrm{~h}^{[42]}$

\section{MARKATED PRODUCT OF CLOVE:}

DABUR HERBAL CLOVE TOOTHPASTE:

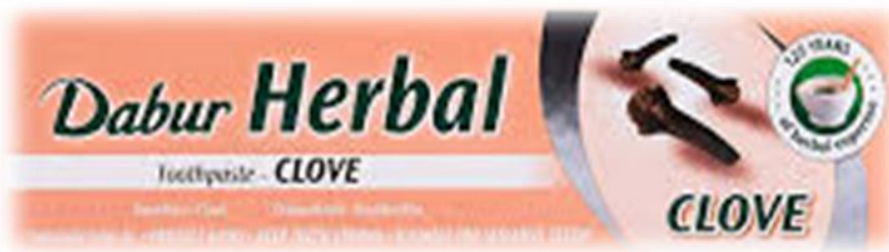

Uses:

Dabur Toothpaste with Cloves is a great tasting toothpaste made with all-natural ingredients. It combines natural extracts with cloves which is known for its antibacterial and analgesic properties. It helps fight germs and prevents tooth decompose and cavities and its analgesic action help reduce toothaches

\section{HERBINS CLOVE OIL}

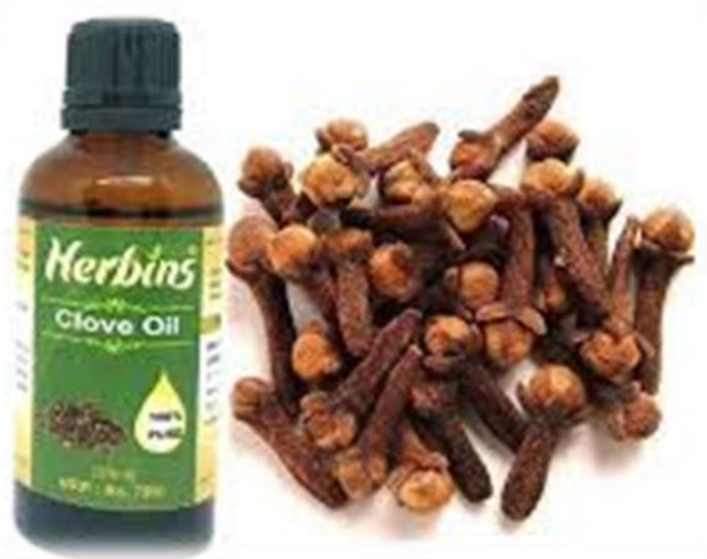

\section{Uses of Herbin Clove Oil}

- As an antimicrobial, to help kill bacteria.

- As a pain reliever for conditions such as toothache and muscle pain.

- For digestive upset.

- To relieve respiratory conditions like cough and asthma.

\section{CLOVE POWDER:-}




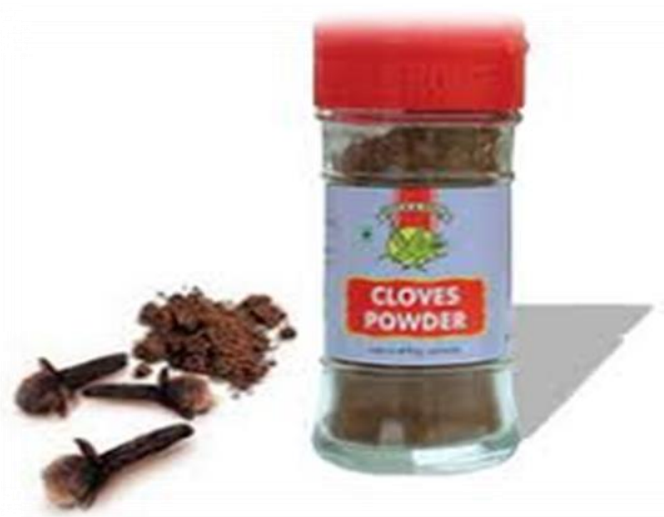

\section{Uses of Clove Powder:-}

1. Contain important nutrients....

2. High in antioxidants. ...

3. May help protect against cancer. ...

4. Can kill bacteria....

5. May improve liver health. ...

6. May help regulate blood sugar. ...

7. May promote bone health. ...

8. May reduce stomach ulcers.

\section{CLOVE SHAMPOO:-}

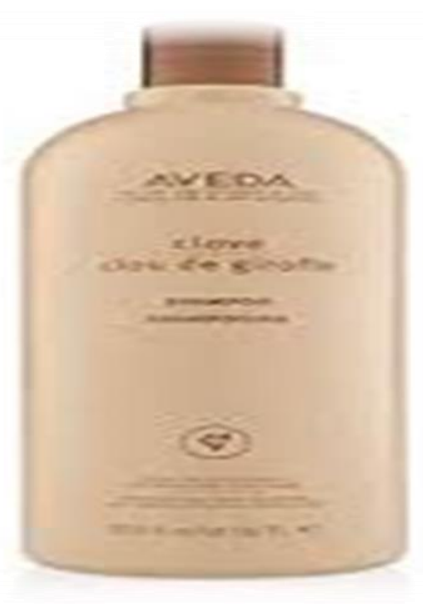

\section{Clove Shampoo Uses:}

\section{Eliminates Dandruff:}

one of the several clove oil uses for hair include its ability to get free of dandruff and soothe dry, aggravated scalp conditions. To treat dandruff, you can add around 10 to 12 drops of clove oil to 8 ounces of your regular shampoo and wash your hair with it.

\section{CONCLUSION:}


Based on this above information it could be conclude that the clove is a very interesting and important plant which is used for the treatment of various medical conditions because it has various active constituent present in it but most important constituent that is eugenol have various pharmacological activity and for this all miraculous activity of this plant we can confirm that why this plants has been engaged for various centuries.

\section{REFERENCE:}

1. Shan B, Cai YZ, Sun M, Corke H. Antioxidant capacity of 26 spice extracts and characterization of their phenolic constituents. J Agric Food Chem. 2005;53(20):77497759.

2. Kamatou GP, Vermaak I, Viljoen AM. Eugenol--from the remote Maluku Islands to the international market place: a review of a remarkable and versatile molecule. Molecules. 2012;17(6):6953-6981.

3. Filho GA, Cesar JO, Ramos JV. Itabuna: CEPLAC; 2013. [Cravo from India] [Online] Available from: http://www.ceplac.gov.br/radar.htm. [Accessed on 21st April, 2013]. Portuguese.

4. Oliveira RA, Oliveira FF, Sacramento CK. [Essential oils: prospects for agribusiness spices in Bahia] Bahia Agric. 2007;8(1):46-48. Portuguese.

5. Oliveira RA, Reis TV, Sacramento CK, Duarte LP, Oliveira FF. Volatile chemical constituents of rich spices in eugenol. Rev Bras Farmacognosia. 2009;19(3):771-775

6. .http://www.pharmacy180.com/article/clove-247/

7. https://www.truthinaging.com/ingredients/eugenia-caryophyllus

8. https://www.google.com/search?q=common+name+of+clove\&oq=common+name+of+ clove \&aqs $=$ chrome..69i57j016.231

9. http://www.earthendelight.com/earthendelight-organic-productcloves.html\#.XmtRmqMzbIU

10. Thangaselvabai, R.R. Kennedy, J.P. Joshua, M. Jayasekar. (2010). Clove (Syzygium aromaticum)-- The spicy flower bud of significance-a review. Agricultural Reviews. 31(1).

11. Rovio, S.; Hartonen, K.; Holm, Y.; Hiltunen, R.; Riekkola, M.- L. (7 February 2000). "Extraction of clove using pressurized hot water". Flavour and Fragrance Journal. 14 (6).

12. Hekimoğlu MA, Ergun M. Evaluation of clove oil as anaesthetic agent in fresh water angelfish, Pterophyllumscalare. Pak J Zool. 2012;44(5):1297-1300 
13. Gopalakrishnan N, Narayanan CS, Mathew AG. Chemical composition of Indian clove bud, stem and leaf oils. Indian Perfumers. 1988; 32: 229-235.

14. Pino JA, Marbot R, Aguero J, Fuentes V. Essential oil from buds and leaves of clove (Syzygium aromaticum (L.) Merr. et Perry) grown in Cuba. Journal of Essential Oil Research. 2001; 13(4): 278-279.

15. Gopalakrishnan, N. and Narayanan, C.S. Composition of clove leaf oil during leaf growth. Indian Perfumers. 1988; 32(2): 130- 132.

16. Nonaka G, Harada M, Nishioka I. Eugenin, a new ellagitannin from cloves. Chemical and Pharmacological Bulletin.1980; 28: 685-687.

17. Tanaka T, Orii Y, Nonaka G, Nishioka I. Tannins and related compounds. CXXIII. Chromone, acetophenone and phenyl propanoid glycosides and their galloyl and/or hexahydroxy phenoyl esters from leaves of Syzygium aromaticum Merr and Perry. Chemical Pharmaceutical Bulletin. 1993; 28: 685-687.

18. Narayanan CR, Natu AA. Triterpene acids of Indian clove buds. Phytochemistry.1974; 13(9):1999-2000.

19. Brieskorn $\mathrm{CH}$, Munzhuber K, Unger G. Crataegolsaure and steroid glukoside aus blutenknospen von Syzygium aromaticum. Phytochemistry. 1975; 14: 2308-2309.

20. Zhang YW, Chen Y. Isobiflorin, a chromone-C-glucoside from cloves (Eugenia caryophyllata). Phytochemistry. 1997; 45: 401- 403.

21. Nassar MI. Flavonoid triglycosides from the seeds of Syzygium aromaticum. Carbohydrate Research. 2006; 341: 160-163.

22. Cai L, CD Wu. Compounds from Syzygium aromaticum possessing growth inhibitory activity against oral pathogens. J. Nat. Prod. 1996; 59(10): 987-990.

23. Trongtokit Y, Rongsriyam Y, Komalamisra N, Apiwathnasorn C. Comparative repellency of 38 essential oils against mosquito bites. Phytotherapy Research. 2005; 19(4): 303-309.

24. Devi KP, Nisha SA, Sakthivel R, Pandian SK. Eugenol (an essential oil of clove) acts as an antibacterial agent against Salmonella typhi by disrupting the cellular membrane. J Ethnopharmacol. 2010;130(1):107-115.

25. Chami F, Chami N, Bennis S, Trouillas J, Remmal A. Evaluation of carvacrol and eugenol as prophylaxis and treatment of vaginal candidiasis in an immunosuppressed rat model. J Antimicrob Chemother. 2004;54(5):909-914.

26. Rana IS, Rana AS, Rajak RC. Evaluation of antifungal activity in essential oil of the 
Syzygiumaromaticum (L.) by extraction, purification and analysis of its main component eugenol. Braz J Microbiol. 2011;42(4):1269-1277.

27. Guénette SA, Ross A, Marier JF, Beaudry F, Vachon P. Pharmacokinetics of eugenol and its effects on thermal hypersensitivity in rats. Eur J Pharmacol. 2007;562(1-2):60-67.

28. Emergence of a new antibiotic resistance mechanism in India, Pakistan, and the UK: a molecular, biological, and epidemiological study Kumarasamy, Karthikeyan K et al. The Lancet Infectious Diseases , Volume 10 , Issue 9 , 597 - 602

29. Parle M, Khanna D. Clove: a champion spice. International Journal of Research in Ayurveda and Pharmacy.2011;2(1):47-54.

30. B.H. Abdullah, S.F. Hatem, W. Jumaa. (2015). A comparative study of the antibacterial activity of clove and rosemary essential oils on multidrug resistant bacteria. UK Journal of Pharmaceutical and Biosciences. 3(1): 18-22.

31. M.-J. Park, K.-S. Gwak, I. Yang, W.-S. Choi, H.-J. Jo, J.-W. Chang, E.-B. Jeung, I.-G. Choi. (2007). Antifungal activities of the essential oils in Syzygium aromaticum (L.) Merr. Et Perry and Leptospermum petersonii Bailey and their constituents against various dermatophytes. The Journal of Microbiology. 45(5): 460-465.

32. P.K. Sofia, R. Prasad, V.K. Vijay, A.K. Srivastava. (2007). Evaluation of antibacterial activity of Indian spices against common foodborne pathogens. International journal of food science \& technology. 42(8): 910-915.

33. H. Dorman, S.G. Deans. (2000). Antimicrobial agents from plants: antibacterial activity of plant volatile oils. Journal of applied microbiology. 88(2): 308-316.

34. D. Slameňová, E. Horváthová, L. Wsólová, M. Šramková, J. Navarová. (2009). Investigation of anti-oxidative, cytotoxic, DNA-damaging and DNA-protective effects of plant volatiles eugenol and borneol in human-derived HepG2, Caco-2 and VH10 cell lines. Mutation Research/Genetic Toxicology and Environmental Mutagenesis. 677(1-2): 46-52.

35. M.M. Khan, M. Iqbal, M.A. Hanif, M.S. Mahmood, S.A. Naqvi, M. Shahid, M.J. Jaskani. (2012). Antioxidant and antipathogenic activities of citrus peel oils. Journal of Essential Oil Bearing Plants. 15(6): 972-979.

36. S. Shobana, K.A. Naidu. (2000). Antioxidant activity of selected Indian spices. Prostaglandins, Leukotrienes and Essential Fatty Acids (PLEFA). 62(2): 107-110.

37. R. Ghadermazi, J. Keramat, S. Goli. (2017). Antioxidant activity of clove (Eugenia caryophyllata Thunb), oregano (Oringanum vulgare L) and sage (Salvia officinalis L) 
essential oils in various model systems. International Food Research Journal. 24(4): 1628.

38. K. Chaieb, H. Hajlaoui, T. Zmantar, A.B. Kahla- Nakbi, M. Rouabhia, K. Mahdouani, A. Bakhrouf. (2007). The chemical composition and biological activity of clove essential oil, Eugenia caryophyllata (Syzigium aromaticum L. Myrtaceae): a short review. Phytotherapy research. 21(6): 501-506.

39. M. Thuwaini, M. Abdul-Mounther, H. Kadhem. (2016). Hepatoprotective Effects of the Aqueous Extract of Clove (Syzygium aromaticum) against Paracetamol Induced Hepatotoxicity and Oxidative Stress in Rats. European Journal of Pharmaceutical and Medical Research. 3(8): 36-42.

40. J. Feng, J. Lipton. (1987). Eugenol: antipyretic activity in rabbits. Neuropharmacology. 26(12): 1775-1778.

41. J. Keene, D. Noakes, R. Moccia, C. Soto. (1998). The efficacy of clove oil as an anaesthetic for rainbow trout, Oncorhynchus mykiss (Walbaum). Aquaculture Research. 29(2): 89-101

42. P. Doleželová, S. Mácová, L. Plhalová, V. Pištěková, Z. Svobodová. (2011). The acute toxicity of clove oil to fish Danio rerio and Poecilia reticulata. Acta Veterinaria Brno. 80(3): 305-308. 